\title{
The role of ecotypic variation and the environment on biomass and nitrogen in a dominant prairie grass
}

\author{
Meredith L. Mendola, ${ }^{1}$ Sara G. Baer,${ }^{1,4}$ Loretta C. Johnson, ${ }^{2}$ and Brian R. Maricle ${ }^{3}$ \\ ${ }^{1}$ Department of Plant Biology and Center for Ecology, Southern Illinois University, Carbondale, Illinois 62901 USA \\ ${ }^{2}$ Division of Biology, Kansas State University, Manhattan, Kansas 66506 USA \\ ${ }^{3}$ Department of Biological Sciences, Fort Hays State University, Hays, Kansas 67601 USA
}

\begin{abstract}
Knowledge of the relative strength of evolution and the environment on a phenotype is required to predict species responses to environmental change and decide where to source plant material for ecological restoration. This information is critically needed for dominant species that largely determine the productivity of the central U.S. grassland. We established a reciprocal common garden experiment across a longitudinal gradient to test whether ecotypic variation interacts with the environment to affect growth and nitrogen $(\mathrm{N})$ storage in a dominant grass. We predicted plant growth would increase from west to east, corresponding with increasing precipitation, but differentially among ecotypes due to local adaptation in all ecotypes and a greater range of growth response in ecotypes originating from west to east. We quantified aboveground biomass, root biomass, belowground net primary production (BNPP), root C:N ratio, and $\mathrm{N}$ storage in roots of three ecotypes of Andropogon gerardii collected from and reciprocally planted in central Kansas, eastern Kansas, and southern Illinois. Only the ecotype from the most mesic region (southern Illinois) exhibited more growth from west to east. There was evidence for local adaptation in the southern Illinois ecotype by means of the local vs. foreign contrast within a site and the home vs. away contrast when growth in southern Illinois was compared to the most distant site in central Kansas. Root biomass of the eastern Kansas ecotype was higher at home than at either away site. The ecotype from the driest region, central Kansas, exhibited the least response across the environmental gradient, resulting in a positive relationship between the range of biomass response and precipitation in ecotype region of origin. Across all sites, ecotypes varied in root $\mathrm{C}: \mathrm{N}$ ratio (highest in the driest-origin ecotype) and $\mathrm{N}$ storage in roots (highest in the most mesic-origin ecotype). The low and limited range of biomass, higher $\mathrm{C}: \mathrm{N}$ ratio of roots, and lower $\mathrm{N}$ storage in the central Kansas ecotype relative to the southern Illinois ecotype suggests that introducing ecotypes of $A$. gerardii from much drier regions into highly mesic prairie would reduce productivity and alter belowground ecosystem processes under a wide range of conditions.
\end{abstract}

Key words: Andropogon gerardii; ecosystem function; ecotype; local adaptation; productivity; restoration; roots.

\section{INTRODUCTION}

Knowledge of local adaptation among plant populations is needed to predict how species will cope with climate change (Aitken and Whitlock 2013, Liancourt et al. 2013, De Frenne et al. 2014) and make informed decisions about where to source plant material for ecological restoration under current and future conditions (Jones 2013). The persistence of plant populations in a location experiencing rapid environmental change will depend on immigration of adaptive genes, in-situ adaptation, or phenotypic plasticity (Aitken et al. 2008, Nicotra et al. 2010). In the absence of these coping mechanisms, translocation may be required to preserve a species (Weeks et al. 2011, Lunt et al. 2013). Alterna-

Manuscript received 4 August 2014; revised 9 January 2015; accepted 3 March 2015. Corresponding Editor: S. K. Chapman.

${ }^{4}$ Corresponding author. E-mail: sgbaer@siu.edu tively, human intervention can be used to augment genetic diversity by introducing more genetic (ecotypic) variation into existing populations or at the onset of restoration (Broadhurst et al. 2008). Understanding the extent of ecotypic variation and how it interacts with the environment is particularly critical for dominant species because they can exert a strong influence on ecosystem processes (Grime 1998). This is the case in tallgrass prairie, where dominant grasses comprise most of the productivity in regions that have escaped cultivation (Risser et al. 1981). These $\mathrm{C}_{4}$ grasses also drive recovery of ecosystem processes during restoration, such as soil C accrual and increasing nutrient conservation (Baer et al. 2002). Climate of the tallgrass prairie is expected to become more variable and include more prolonged periods with less precipitation (Polley et al. 2013). Thus, knowledge of ecotypic variation in dominant prairie grasses will inform predictions of how this ecosystem will respond to climate change and decisions regarding 
where to source propagules for ecological restoration able to withstand more variable conditions.

Ecotypes share a collection of morphological and physiological traits that evolved from a regional selection pressure (Lowry 2012). Climate was an important driver in development of grassland in the central United States (Axelrod 1985) and a plausible regional selection pressure for the evolution of ecotypes across environmental gradients in this ecosystem. In support of this, ecotypic variation in growth, morphology, behavior, and phenology has been documented in dominant prairie grasses along a latitudinal gradient in tallgrass prairie (McMillan 1964, 1965, 1967) and invoked to explain geographic variation in the functioning of this ecosystem (McMillan 1959, 1969). Climate also varies from west to east in the central U.S. grassland and aboveground net primary productivity (ANPP) increases with precipitation across this gradient (Sala et al. 1988, Lauenroth et al. 1999). Biomass production of $\mathrm{C}_{4}$ grasses, including Andropogon gerardii, is significantly related to precipitation across the Great Plains (Epstein et al. 1998) and in response to water availability within tallgrass prairie (Knapp et al. 2001). Further, there is evidence that aboveground tissue chemistry, leaf morphology, and genetics vary among ecotypes of $A$. gerardii reciprocally planted along a longitudinal gradient with a two-fold increase in mean annual precipitation (MAP; Zhang et al. 2012, Olsen et al. 2013, Gray et al. 2014). There is little consensus on how precipitation affects belowground NPP (BNPP; Hayes and Seastedt 1987, McCulley et al. 2005, Byrne et al. 2013), and no knowledge of ecotypic variation in $A$. gerardii belowground, where the majority of plant biomass in tallgrass prairie resides (Johnson and Matchett 2001, Nippert et al. 2012). In a greenhouse study, Avolio and Smith (2013) found the most significant effects of watering treatments among genotypes of $A$. gerardii occurred belowground. The differential response of genotypes from one population in eastern Kansas to variation in a single resource suggests potential for much greater variation in belowground response to a suite of different environmental conditions among ecotypes originating from more distant populations, i.e., from central Kansas to southern Illinois.

Reciprocal common gardens can be used to test for local adaptation in plants (Savolainen et al. 2013). Two common approaches to quantifying local adaptation include comparison of populations in their home environment to a different environment (home vs. away) and the response of a local population at home relative to populations transplanted from foreign environments (local vs. foreign). The latter has been advocated as the diagnostic test for local adaptation because it is more relevant to the historical forces of natural selection (Kawecki and Ebert 2004). Blanquart et al. (2013) suggest that local adaptation should be defined in terms of a metapopulation and quantify the proportion of spatial variation in the average response resulting from adaptation to local conditions. These authors recommend quantifying local adaptation from the difference in the average fitness of all sympatric (within the home site) and allopatric (transplanted to other sites) populations sampled after deme (e.g., provenance, population, or ecotype) and habitat (e.g., site) quality effects are removed.

Transplant experiments can also reveal the extent to which a species can elicit a range of phenotypes (as measured via the relative trait range or RTR) in response to different environmental conditions and how this response relates to an environmental variable (Richardson et al. 2001). In general terms, the RTR index uses an expectation that the response of a population will be higher in one environment than another and is expressed relative to the maximum response of all populations in both environments. A positive RTR indicates the response is in the direction expected and the magnitude indicates the range in the response. This index has been used to reveal relationships between plasticity in leaf traits from populations originating across a rainfall gradient and the MAP in a population's region of origin (McLean et al. 2014). When applied to biomass produced in a reciprocal common garden, this index can indicate the degree to which sensitivity of plant growth responds according to expectations of the environment or local adaptation, and is related to an environmental variable in a population's region of origin.

We established a reciprocal common garden experiment across a longitudinal gradient that contained a two-fold increase in MAP from west to east and different soil conditions at each site to test for local adaptation in a dominant species and quantify whether the range of trait response corresponds to MAP in the ecotype's region of origin. Andropogon gerardii was used in this study because this species can comprise up to $80 \%$ of the aboveground biomass (Risser et al. 1981), has been shown to determine ecosystem functioning (Smith and Knapp 2003), and plant species diversity is suppressed by its dominance (Collins and Calabrese 2012) in tallgrass prairie. We measured above and belowground biomass, BNPP, root tissue $\mathrm{C}: \mathrm{N}$ ratio, and $\mathrm{N}$ storage in roots because they can confer a fitness advantage in species that reproduces predominantly by tillering (Benson and Hartnett 2006). These responses are also highly relevant to predicting how ecosystem processes (e.g., productivity and decomposition) in prairie dominated by $A$. gerardii will respond to environmental change.

Three ecotypes of A. gerardii were collected from and reciprocally planted in central Kansas, eastern Kansas, and southern Illinois. We hypothesized that growth and $\mathrm{N}$ content would be affected by an interaction between ecotype and the environment (Fig. 1A) due to differences in the range of responses among ecotypes across the gradient. A directional change in an ecotype's response across the gradient would indicate an over- 

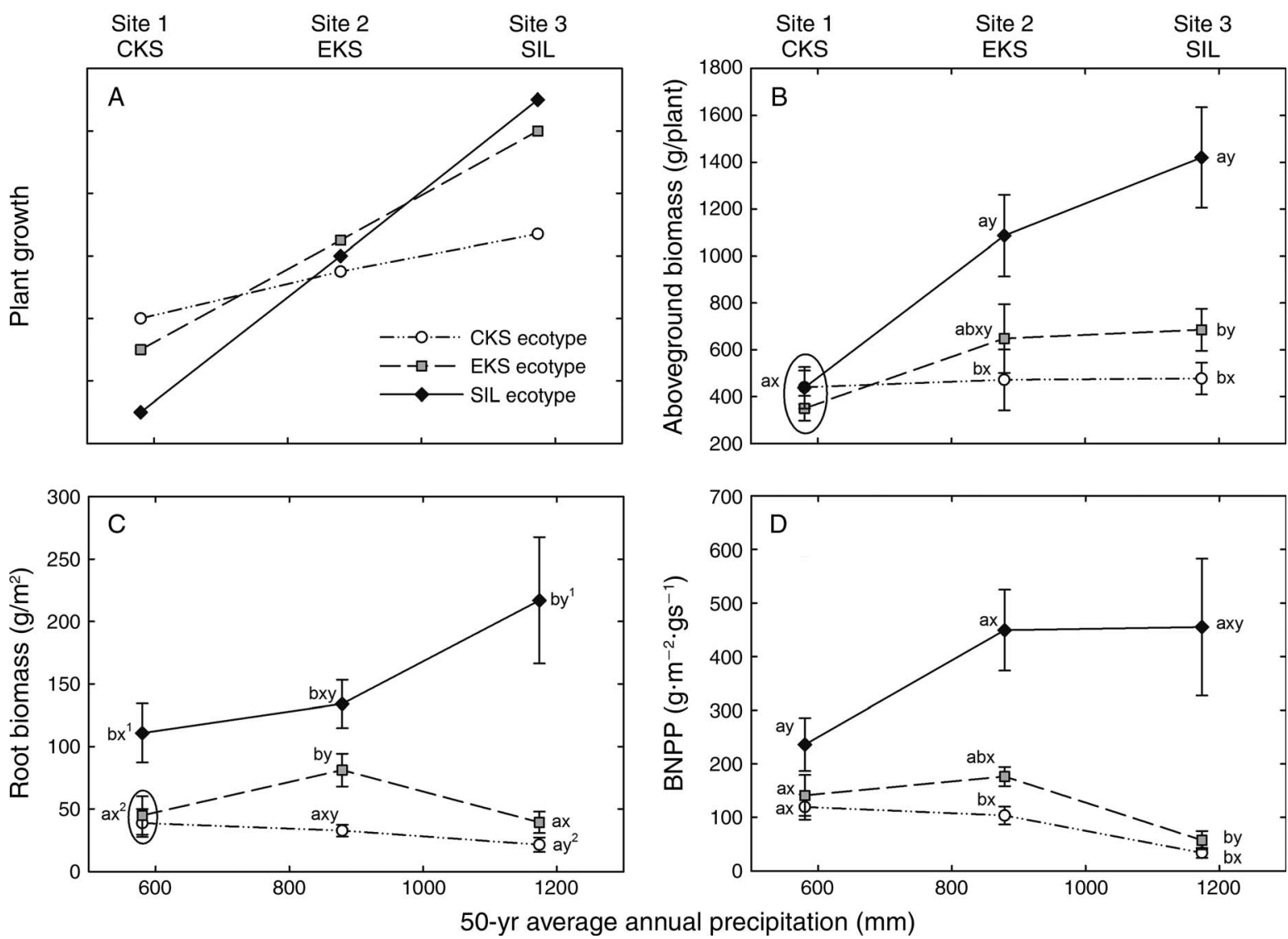

FIG. 1. Interactions between ecotype and (A) site as hypothesized and observed in (B) aboveground biomass, (C) root biomass, and (D) belowground net primary productivity (BNPP) over the 16-week growing season (gs) incubation period. Each symbol represents the least squares mean \pm SE. Ecotype home environments and corresponding abbreviations are as follows: CKS, central Kansas; EKS, eastern Kansas; and SIL, southern Illinois. Letters a-c indicate differences among ecotypes within a site and letters $\mathrm{x}-\mathrm{Z}$ indicate differences among sites within an ecotype. Means accompanied by the same letter were not significantly different $(P>$ 0.05; different superscript numerals indicate contrasts with $P<0.06:{ }^{1} \mathrm{SIL}$ ecotype compared between S1 and S3; ${ }^{2} \mathrm{CKS}$ ecotype compared between S1 and S3). Symbols contained within an ellipse were not significantly different $(P>0.05$ for ecotype comparisons within a site).

whelming influence of climate (precipitation) on growth, as grasslands with highly contrasting soil texture and nutrient status can exhibit similar productivity (Baer et al. 2010); responses inconsistent with this would suggest other factors (e.g., soil mutualists) have more influence on growth and N content. Because ANPP of tallgrass prairie is responsive to water availability (Knapp et al. 2001), we predicted that growth of all ecotypes would increase from west to east, corresponding with increasing precipitation. We also predicted local adaptation would be evident from more growth in an ecotype's local or home environment relative to foreign ecotypes in that environment. Ecotype responses were also compared at home relative to away sites to reveal whether local adaptation resulted from factors other than climate (e.g., soil). We applied the sympatric vs. allopatric contrast to determine whether this test for local adaptation explained patterns that only partially conformed to our predominantly precipitation-based hy- pothesis. Last, we tested whether RTR index changed in the direction expected as a result of the environment (more growth with increasing precipitation) or local adaptation (more growth at home). We predicted the RTR index to result in positive values and increase with MAP in the ecotype region of origin if climate is the predominant control on ecotypic variation. If the home environment was expected to result in more growth, then an increase in the RTR index with MAP in ecotype region of origin would indicate local adaptation to factors other than climate, e.g., mutualisms with soil biota (Schultz et al. 2001, Johnson et al. 2010, Ji et al. 2013).

We measured root $\mathrm{C}: \mathrm{N}$ ratio and $\mathrm{N}$ storage in roots of A. gerardii because $\mathrm{N}$ content strongly influences litter decomposition (Cornwell et al. 2008). We expected nutrients to be more available in the mesic site, corresponding with conditions more conducive for $\mathrm{N}$ supply through microbial activity (McCulley et al. 
2005). Plants form associations with arbuscular mycorhhizae fungi (AMF) to increase $\mathrm{N}$ and $\mathrm{P}$ acquisition (Smith et al. 2009), and A. gerardii dependency on AMF has been shown to vary with available $\mathrm{N}$ and $\mathrm{P}$ (Ji et al. 2013). There is also evidence that the Illinois ecotype of A. gerardii is less dependent on AMF than an ecotype from eastern Kansas (Schultz et al. 2001). We hypothesized root $\mathrm{C}: \mathrm{N}$ ratio and $\mathrm{N}$ storage in roots would exhibit an interaction between ecotype and environment resulting from a greater ability of the Illinois ecotype to acquire $\mathrm{N}$ in roots under mesic conditions relative to drier conditions, where greater dependency on AMF would be needed for $\mathrm{N}$ acquisition.

\section{Methods \\ Study site characteristics}

Common gardens were established in 2009 at three locations along a longitudinal gradient within the historical range of temperate grassland designated as mixed and tallgrass prairie in North America. The study sites were located in central Kansas, eastern Kansas, and southern Illinois. All gardens contained silt loam soils and were previously cultivated (Table 1). The common garden in central Kansas (Site 1) was at the Kansas State University (KSU) Agricultural Research Extension Station in Hays, Kansas. Average annual rainfall at this site has been $582 \mathrm{~mm}$, based on a $50-\mathrm{yr}$ record (data available online). ${ }^{5}$ The eastern Kansas common garden (Site 2) was at the USDA Plant Materials Center, $\sim 9 \mathrm{~km}$ from Manhattan, Kansas. This region has received an average of $871 \mathrm{~mm}$ of precipitation over the past $50 \mathrm{yr}$ (see footnote 5). The southern Illinois common garden (Site 3) was at Southern Illinois University's Agricultural Research Center in Carbondale, Illinois. Precipitation at this site has averaged $1167 \mathrm{~mm}$ for the past 50 yr (see footnote 5). In 2011, the year of study, annual precipitation approximated the 50 -yr average at both Kansas sites (Table 1). At the Illinois site, total precipitation was $570 \mathrm{~mm}$ higher than the 50 -yr average, but $74 \%$ of this was received outside of the study period (31\% prior to 12 May and $43 \%$ after 4 September). Growing-season temperature was highest at the driest site in central Kansas and declined to the east, with a $1.4^{\circ} \mathrm{C}$ difference from central Kansas to southern Illinois.

Percent $\mathrm{C}$ and $\mathrm{N}$, texture, cation exchange capacity (CEC), available phosphorus, and $\mathrm{pH}$ were measured at the start of the experiment in 2009 to characterize the soil at each common garden. We removed 20 soil cores ( $2 \mathrm{~cm}$ diameter $\times 10 \mathrm{~cm}$ deep) from each site. Soil cores were composited, sieved $(2 \mathrm{~mm})$, and air dried. Two $50 \mathrm{~g}$ subsamples were dried at $55^{\circ} \mathrm{C}$, ground to a fine powder, and analyzed for percent $\mathrm{C}$ and $\mathrm{N}$ on a Flash 2000 Organic Elemental Analyzer (Thermo Fisher Scientific, Cambridge, UK). A 200-g subsample was sent to the

${ }^{5}$ http://www.ncdc.noaa.gov/data-access/quick-links\#ghcn
Kansas State University Soil Testing Lab to determine texture and cation exchange capacity (CEC). Bray P was determined using $2 \mathrm{~g}$ of air-dried soil extracted with 20 $\mathrm{mL}$ of $0.025 \mathrm{~mol} / \mathrm{L} \mathrm{HCl}+0.03 \mathrm{~mol} / \mathrm{L} \mathrm{NH}_{4} \mathrm{~F}$ for $1 \mathrm{~min}$ on a shaker and filtered immediately through a $0.4-\mu \mathrm{m}$ filter. Phosphate-P was determined on a Flow IV Autoanalyzer (OI Analytical, College Station, Texas, USA).

Soil properties varied across sites (Table 1). Available $\mathrm{P}$ increased west to east by a factor of 10.3 from central Kansas to southern Illinois at the onset of the experiment. Soil $\mathrm{pH}$ declined from west to east, as would be expected with increased weathering in response to greater annual precipitation. Cation exchange capacity did not change directionally across the gradient but reflected soil texture, namely increasing with percent clay. The wettest site in southern Illinois contained the most fertile soil, as measured by percent $\mathrm{C}$ and $\mathrm{N}$, but soil fertility did not vary according to a gradient among sites. Tillage degrades soil structure, lowers organic matter storage, alters the microbial community composition, and reduces biomass of AMF, which are common conditions at the onset of grassland restoration (Baer et al. 2010, Bach et al. 2010). Andropogon gerardii is dependent on AMF, which are reduced in response to tillage and nutrient inputs, but increase exponentially in response to $\mathrm{C}_{4}$ grass establishment (Bach et al. 2010). We presume AMF were present in the soil at all sites or plants would not have established well. Results from this study are interpreted in the context of reciprocally transplanting $A$. gerardii in agricultural soil, where abundance of locally adapted AMF is likely lower and composition of the soil microbial community is likely distinct from never cultivated prairie.

\section{Focal species}

Andropogon gerardii is a wind-pollinated, rhizomatous, $\mathrm{C}_{4}$ grass that occurs throughout the United States east of the Rocky Mountains. This species is an obligate out-crosser, with strong self-incompatibility (Norrmann et al. 1997). Reproduction is primarily through vegetative growth in the form of reproductive and nonreproductive tillers (Benson and Hartnett 2006). As with many grasses, A. gerardii contains a large polyploid genome consisting of $6 \mathrm{X}$ and $9 \mathrm{X}$ cytotypes (Keeler et al. 1986). Kansas contains more contiguous prairie dominated by this species than Illinois, where $>99.9 \%$ of this ecosystem has been converted to row-crop agriculture (Samson and Knopf 1994). Genetic studies of A. gerardii demonstrate that small, highly fragmented populations contain high genetic diversity (Gustafson et al. 1999, Gray et al. 2014), and the genetic structure of the Illinois populations used in this study was distinct from the KS populations (Gray et al. 2014).

\section{Reciprocal common garden design}

In the autumn 2008, A. gerardii seeds were collected from four prairies (four populations within each 
TABLE 1. Common garden site locations, climate, and soil characteristics.

\begin{tabular}{|c|c|c|c|}
\hline Parameter & $\begin{array}{c}\text { Site } 1 \\
\text { central KS }\end{array}$ & $\begin{array}{c}\text { Site } 2 \\
\text { eastern KS }\end{array}$ & $\begin{array}{c}\text { Site } 3 \\
\text { southern IL }\end{array}$ \\
\hline Nearest city & Hays & Manhattan & Carbondale \\
\hline Latitude & $38^{\circ} 51^{\prime} \mathrm{N}$ & $39^{\circ} 08^{\prime} \mathrm{N}$ & $37^{\circ} 41^{\prime} \mathrm{N}$ \\
\hline Longitude & $99^{\circ} 19^{\prime} \mathrm{W}$ & $96^{\circ} 38^{\prime} \mathrm{W}$ & $89^{\circ} 14^{\prime} \mathrm{W}$ \\
\hline 2011 annual PPT (mm) & 486 & 881 & 1738 \\
\hline 2011 GS PPT (mm) & 275 & 379 & 435 \\
\hline 2011 average annual $\mathrm{T}\left({ }^{\circ} \mathrm{C}\right)$ & 13.6 & 12.7 & 13.6 \\
\hline $2011 \mathrm{GS} \mathrm{T}\left({ }^{\circ} \mathrm{C}\right)$ & 25.4 & 24.7 & 24.0 \\
\hline Soil taxonomy & $\begin{array}{c}\text { fine, smectic, mesic typic } \\
\text { Arguistoll }\end{array}$ & $\begin{array}{l}\text { coarse-silty, mixed, } \\
\text { superactive, nonacid mesic } \\
\text { typic Udifluvents }\end{array}$ & $\begin{array}{l}\text { fine-silty, mixed, } \\
\text { superactive, mesic, } \\
\text { Fragiaquic Hapludalfs }\end{array}$ \\
\hline CEC (meq/100 g) & 25.1 & 8.5 & 13.7 \\
\hline$\% \mathrm{C}$ & 1.88 & 0.71 & 2.67 \\
\hline$\% \mathrm{~N}$ & 0.17 & 0.06 & 0.21 \\
\hline$\%$ sand, silt, clay & $22,59,20$ & $41,51,8$ & $8,79,14$ \\
\hline $\mathrm{PO}_{4}^{\equiv}(\mu \mathrm{g} / \mathrm{g}$ soil $)$ & 8.3 & 29.3 & 85.6 \\
\hline $\mathrm{pH}^{4}$ & 7.5 & 5.9 & 4.9 \\
\hline
\end{tabular}

Notes: Annual and growing season (GS; coinciding with 16-week root ingrowth bag incubation) precipitation (PPT) and temperature (T) were summarized from NOAA weather stations (see footnote 5) in Kansas (KS) and Illinois (IL). CEC is cation exchange capacity.

ecotype) located within $150 \mathrm{~km}$ of the Illinois common garden site and $50 \mathrm{~km}$ from each common garden site in Kansas. Ecotypes were assigned to regions where the prairie collection sites were located: central Kansas (CKS), eastern Kansas (EKS), and southern Illinois (SIL). Seeds were germinated and grown in a greenhouse during the summer 2009; Olsen et al. (2013) provide information on greenhouse conditions and plant care. Seedlings were transplanted into the common gardens in August 2009 according to a randomized complete block design. Each block contained 12 A. gerardii plants, one from each population, spaced $\sim 0.5 \mathrm{~m}$ apart within a matrix of black landscaping plastic to discourage the growth of other species. Gardens were weeded regularly. We randomly selected two populations within each ecotype and sampled these populations from five blocks at each site. The same populations were sampled at all sites. To summarize, we sampled two populations within each of the three ecotypes (six populations total) from five blocks at each of the three sites (five replicates per population per site; 30 samples per site; 90 samples total).

\section{Plant responses}

Root biomass, root $\mathrm{C}: \mathrm{N}$ ratio, and $\mathrm{N}$ storage in roots were measured in May 2011, whereas BNPP was measured over the 2011 growing season, and aboveground biomass was collected at the end of the 2011 growing season. One soil core $(5.5 \mathrm{~cm}$ diameter) was taken $25 \mathrm{~cm}$ from the central tiller of each plant to a depth of $20 \mathrm{~cm}$. Each soil core was passed through a 4$\mathrm{mm}$ sieve, all belowground biomass was immediately hand picked from the sample and placed in an envelope. The root-free soil was placed in a fiberglass $(1 \times 1 \mathrm{~mm}$ mesh screen) ingrowth bag with the same dimensions as the soil core (see Plate 1). Each ingrowth bag was returned to the hole where the soil core was extracted.
Root ingrowth bags remained in the field for 16 weeks. In September 2011, root ingrowth bags were removed by cutting into the soil around each root bag. At the time root ingrowth bags were retrieved, each plant was clipped to $\sim 2 \mathrm{~cm}$ above the soil surface and dried at $60^{\circ} \mathrm{C}$ to quantify aboveground biomass.

In the laboratory, belowground biomass retrieved from the cores in May and root ingrowth bags in September were carefully examined to retrieve true roots (rhizomes not included), washed free of soil, dried at $55^{\circ} \mathrm{C}$, and weighed. Percent $\mathrm{C}$ and $\mathrm{N}$ were determined from roots used for biomass. All roots were ground to a fine powder and a $5-10 \mathrm{mg}$ subsample was analyzed for percent $\mathrm{C}$ and $\mathrm{N}$. Root biomass and $\mathrm{N}$ storage in roots were converted to $\mathrm{g} \mathrm{m}^{-2}$.

\section{Relative trait range index}

The relative trait range or RTR index is determined from the difference in a trait value of a population in an environment expected to produce a higher trait value compared to that in an environment expected to produce a lower trait value, relative to the maximum value of all populations in both environments (Richardson et al. 2001). Positive values indicate the difference is in the direction expected and the magnitude of the value indicates the extent of trait variation (or sensitivity of response). The RTR index was calculated in two ways to explore whether precipitation $\left(\mathrm{RTR}_{1}\right)$ or local adaptation to factors other than climate $\left(\mathrm{RTR}_{2}\right)$ explained whether sensitivity of ecotype biomass responses were related to MAP using the following equation:

$$
\begin{gathered}
R T R=[(\text { ecotype mean in environment } 1) \\
\frac{-(\text { ecotype mean in environment } 2)]}{\text { (max observed mean value across }} \\
\text { all ecotypes in both environments }) .
\end{gathered}
$$


Environment 1 was the common garden site expected to produce the higher response value (higher precipitation in $\mathrm{RTR}_{1}$ and the ecotype's home site in $\mathrm{RTR}_{2}$ ) and environment 2 is the common garden site expected to produce the lower response value (lower precipitation in $\mathrm{RTR}_{1}$ and the ecotypes response when planted away from home in $\mathrm{RTR}_{2}$ ). The least squares mean response was calculated for each ecotype in each site. We calculated the $\mathrm{RTR}_{1}$ index using all possible site (environment) comparisons for each ecotype (S1 v. S2, $\mathrm{S} 1$ v. S3, and S2 v. S3; nine comparisons) and the RTR 2 index for each ecotype using the value at the home compared to those at both of the away sites (six comparisons).

\section{Statistical analyses}

All plant responses were analyzed for fixed main effects and interactions between site and ecotype using the mixed-model procedure in SAS (SAS Institute 2011). Block, population nested within ecotype, and genotype nested within population and ecotype were regarded as random effects. Degrees of freedom were estimated using the Kenwood-Rogers method (Littell et al. 2006). We included the nested random effect genotype(population ecotype) because $A$. gerardii is an obligate outcrossing species, so each transplanted individual represented a unique genotype. The least-squares means procedure was used to determine differences in main effect means. If a significant interaction was present, we used contrast statements to test for local adaptation. All data were $\log$-transformed (or $\log [x+1]$ if data contained values $<1$ ) to normalize residuals prior to analysis. Significance was assigned at $\alpha=0.05$.

Tests for local adaption.-Contrast and estimate statements were used in the mixed model analysis to perform the local vs. foreign test for local adaptation by comparing each ecotype's response at home to the response of foreign ecotypes in that site. Contrast and estimate statements were also used in the mixed model analysis to perform the home vs. away test for local adaptation by comparing each ecotype's response at home relative to away sites. We also performed the sympatric vs. allopatric test for local adaptation (Blanquart et al. 2013). This contrast tests the null hypothesis that means of the sympatric and allopatric distributions are not different after accounting for effects of site and ecotype in an analysis of variance. The mean response of each ecotype was calculated for each site and assigned as sympatric in the site nearest the ecotype's population of origin and allopatric at all other sites. We included site, ecotype, and sympatric-allopatric assignment (SA) as fixed factors in the general linear models procedure in SAS (SAS Institute 2011). A significant effect of SA $(P<0.05)$, and more specifically, a larger least squares mean of ecotypes planted in sympatry than allopatry, indicates local adaption (Blanquart et al. 2013). Variables were log-transformed if needed to achieve normally distributed residuals.
Lastly, we explored whether each RTR index was related to MAP using linear regression. The ecotype RTR response was the dependent variable and mean annual precipitation (MAP) in the ecotype's site of origin was the independent variable (McLean et al. 2014).

\section{Results \\ Local vs. foreign and home vs. away tests for local adaptation}

Whole-plant aboveground biomass differed among ecotypes across the longitudinal gradient (site $\times$ ecotype, $F_{4,74}=2.59, P=0.043$, Fig. 1B), but the interaction only partially conformed to our predictions (Fig. 1A). In southern Illinois, the local SIL ecotype performed better than foreign ecotypes from drier regions in Kansas, where it produced 2.1 and 3.0 times more biomass than the EKS $(P=0.035)$ and CKS $(P=0.003)$ ecotypes, respectively. Aboveground biomass of the SIL ecotype at home in southern Illinois, however, was not consistently higher when compared to away sites. Aboveground biomass of the SIL ecotype was only higher at home compared to its biomass in the driest site, central Kansas $(P<0.001)$. Neither of the Kansas ecotypes produced more aboveground biomass relative to foreign ecotypes in their respective local environments. Aboveground biomass of the EKS ecotype at home was not different from either away site, but was approximately two times higher in the wettest site compared to the driest site $(P=0.014)$. Aboveground biomass of the CKS ecotype did not differ among sites across the gradient and was lower than the SIL ecotype in eastern Kansas $(P=0.007)$ and southern Illinois $(P=$ 0.003).

Root biomass also exhibited a significant interaction between site and ecotype $\left(F_{4,74}=3.07, P=0.021\right.$, Fig. $1 C)$. This interaction resulted from consistently higher biomass in the SIL ecotype relative to both Kansas ecotypes across the gradient, but inconsistent differences between the Kansas ecotypes in each site. At its local site, the SIL ecotype contained more root biomass than the foreign EKS and CKS ecotypes in southern Illinois $(P<0.001)$. Compared to its root biomass at home, the SIL ecotype contained a similar amount of root biomass away in eastern Kansas, but only half as much biomass in the driest site, central Kansas $(P=0.058)$. In eastern Kansas, root biomass of the local EKS ecotype was higher than the foreign ecotype from CKS $(P=$ 0.026), but similar to the foreign ecotype from SIL ecotype $(P=0.002)$. When compared to away sites, the EKS ecotype exhibited a home-site advantage with 1.8 and 2.0 times higher root biomass at home than the drier site in central Kansas $(P=0.019)$ and the wetter site in southern Illinois $(P=0.005)$, respectively. In central Kansas, the local CKS ecotype exhibited lower root biomass than both the foreign SIL $(P=0.005)$ and EKS $(P=0.016)$ ecotypes and modestly more root 

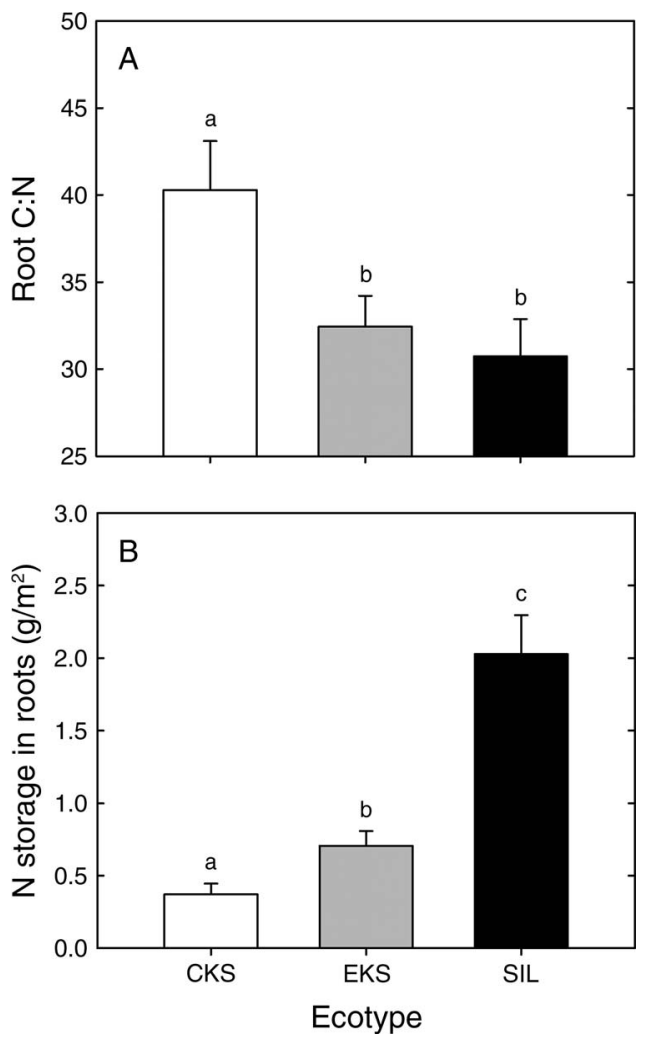

FIG. 2. The main effect of ecotype on (A) root $\mathrm{C}: \mathrm{N}$ ratio and (B) $\mathrm{N}$ storage in roots. Each bar represents the least squares mean; error bars show SE. Means accompanied by the same letter were not significantly different $(P>0.05)$.

biomass at home compared to the wettest away site in southern Illinois $(P=0.057)$.

Similar to aboveground and root biomass, there was an interaction between site and ecotype on BNPP $\left(F_{4,73}\right.$ $=4.72, P=0.002$, Fig. 1D). The local SIL ecotype had $8-$ 12 times higher BNPP than the foreign ecotypes in southern Illinois $(P<0.001)$, but BNPP was not higher at home than either away site in Kansas. In eastern Kansas, the local EKS ecotype did not exhibit higher BNPP than foreign ecotypes. The EKS ecotype produced more than three times the BNPP at home relative to the more mesic away site in southern Illinois $(P=$ 0.001), but BNPP at home was not different from that produced in central Kansas. The BNPP of the CKS ecotype did not differ at home compared to the more mesic away sites, and BNPP of this ecotype was $22 \%$ and $10 \%$ that of the SIL ecotype in eastern Kansas $(P=$ $0.020)$ and southern Illinois $(P<0.001)$, respectively.

Ecotypes differed in root tissue $\mathrm{C}: \mathrm{N}$ ratio $\left(F_{2,77}=\right.$ $7.47, P=0.001)$ and $\mathrm{N}$ storage in roots $F_{2,75}=41.5, P<$ 0.001 ) across all sites (Fig. 2). The root $\mathrm{C}: \mathrm{N}$ ratio in the CKS ecotype was higher than both the EKS $(P=0.008)$ and the SIL $(P<0.001)$ ecotypes across the gradient (Fig. 2A). A strong site effect also occurred for root tissue $\mathrm{C}: \mathrm{N}\left(F_{2,77}=11.80, P<0.001\right)$, with root $\mathrm{C}: \mathrm{N}$ ratio increasing from west to east (central Kansas, 28.2 \pm 1.5; eastern Kansas, $34.41 \pm 1.67$; and southern Illinois, $42.10 \pm 3.16$ ). Differences in root $\mathrm{C}: \mathrm{N}$ were primarily due to differences in percent $\mathrm{N}$. The larger biomass and higher percent $\mathrm{N}$ of root tissue in the SIL ecotype resulted in 2.9 and 5.7 times more $\mathrm{N}$ stored in roots relative to the EKS and CKS ecotypes, respectively $(P<0.001)$. There was also nearly two times more $\mathrm{N}$ stored in the biomass of roots in the EKS ecotype roots relative to the CKS ecotype ( $P=0.015$; Fig. $2 \mathrm{~B})$.

\section{Sympatric vs. allopatric test for local adaptation}

A positive difference in the sympatric vs. allopatric test for local adaptation indicates a larger response in ecotypes planted in sympatry than allopatry and that ecotype explains variation in the response. This test was significant and exhibited a positive difference for root biomass $\left(F_{1,3}=33.7, P=0.010\right)$ and $\mathrm{N}$ storage in roots $\left(F_{1,3}=14.1, P=0.033\right)$. This test was not significant for aboveground biomass or BNPP (Appendix).

\section{Range of trait response}

The magnitude of both RTR indices for aboveground and root biomass tended to be higher for the SIL ecotype than the CKS ecotype, indicating greater sensitivity in the response of the SIL ecotype across the gradient. The RTR index for aboveground biomass increased with 50-yr MAP in ecotype region of origin when the site expected to have higher precipitation was the environment predicted to produce more growth $\left(\mathrm{RTR}_{1}\right.$; Fig. 3A), but not when the home environment was expected to result in more growth $\left(\mathrm{RTR}_{2}\right.$; Fig. $\left.3 \mathrm{~B}\right)$. Both of the RTR indices for root biomass increased with 50 -yr MAP in ecotype region of origin, but there was a much stronger relationship for $\mathrm{RTR}_{2}$ (Figs. 3C and D). The $\mathrm{RTR}_{2}$ for root biomass also consisted of all positive values, indicating that all ecotypes performed better in their respective local (home) environments than when transplanted to other sites. The $\mathrm{RTR}_{1}$ index for BNPP did not increase with 50-yr MAP in ecotype region of origin due to higher BNPP of the EKS ecotype in eastern Kansas than southern Illinois and similar BNPP of the SIL ecotype in eastern Kansas and southern Illinois (Fig. 3E). The RTR 2 index for BNPP was also not related to MAP in ecotype region of origin due to similar BNPP of the SIL ecotype in southern Illinois and eastern Kansas (Fig. 3F).

\section{Discussion}

Ecotypic variation was evident in multiple aspects of growth in $A$. gerardii across a longitudinal gradient and this variation was as pronounced belowground as aboveground. The gradient used in this study presented variation in climate and soil, with increasing precipitation and available $\mathrm{P}$ from west to east, but not all soil properties corresponded to a gradient. In agreement with our hypothesis, there was interaction between ecotype and the environment for all growth responses 


\section{Environment expected response: Site $1<$ Site $2<$ Site 3}
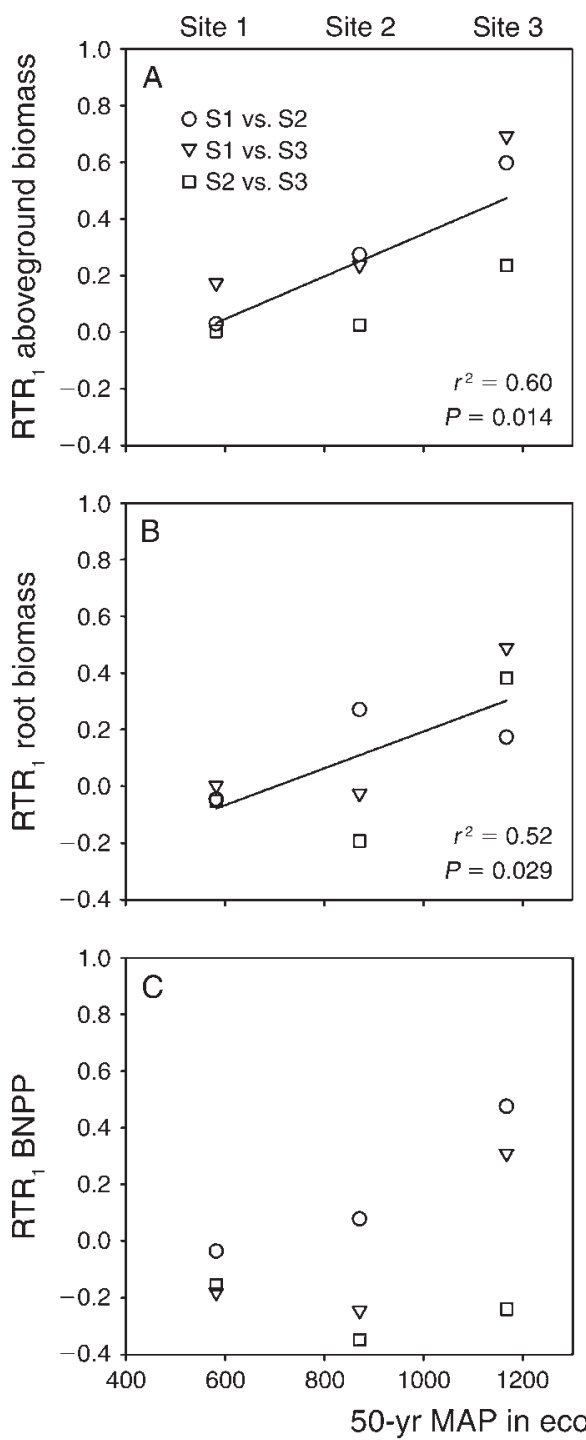

Environment expected response: Home > Away
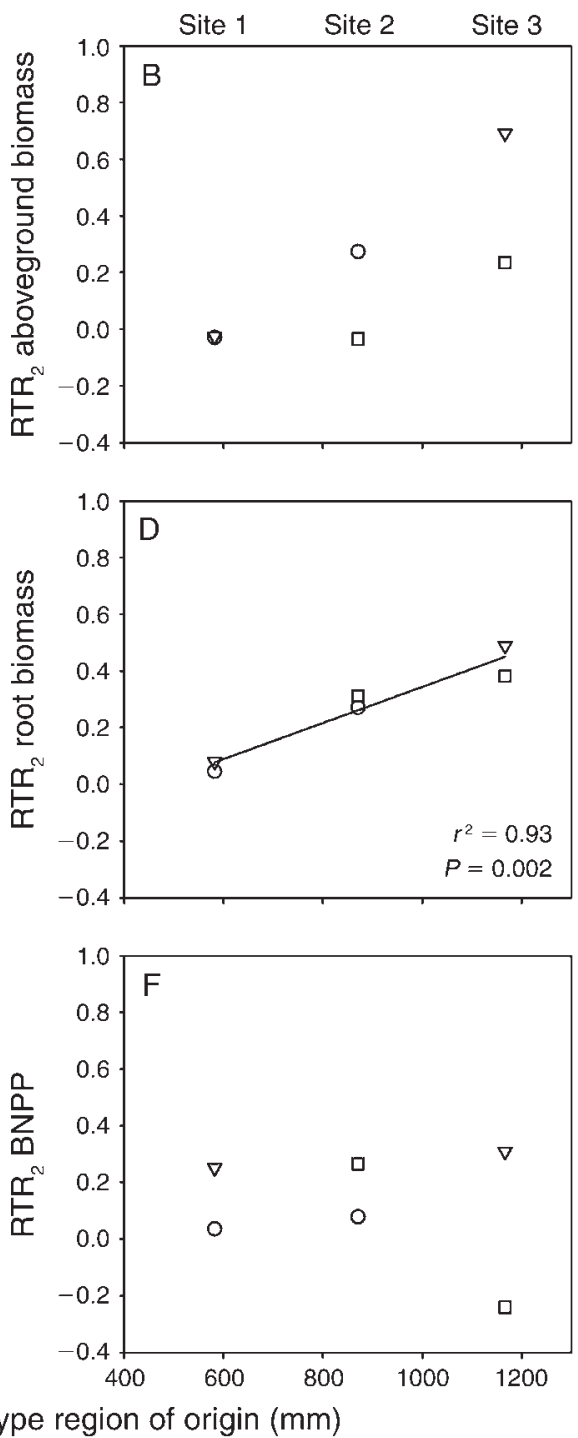

FIG. 3. Relationships between mean annual precipitation (MAP) in each ecotype's region of origin and relative trait responses (RTR) of (A and B) aboveground biomass, $(\mathrm{C}$ and $\mathrm{D})$ root biomass, and (E and $\mathrm{F}$ ) belowground net primary production (BNPP). Panels A, C, and E depict $\mathrm{RTR}_{1}$, determined using higher precipitation as the environment expected to produce the higher growth response. Panels $\mathrm{B}, \mathrm{D}$, and F depict $\mathrm{RTR}_{2}$, determined using the home environment as that expected to produce the higher growth response. A line fit to the data indicates a significant linear relationship $(P<0.05)$. Different symbols indicate the site (S1, S2, S3) comparisons used to calculate the RTR index for each ecotype.

of A. gerardii. This interaction, however, did not completely conform to our hypothesis that predicted biomass and BNPP of all ecotypes would increase from west to east, based on the ANPP response to precipitation in the central U.S. grassland (Sala et al. 1988). Rather, only the ecotype from the most mesic region of origin showed sensitivity to precipitation. Contrary to our expectation, neither ecotype from Kansas grew more in response to higher precipitation. This suggests that productivity across the longitudinal gradient of the prairie ecosystem is partly controlled by ecotypic (genetic) variation in this dominant species, in a similar manner to productivity along the latitudinal gradient studied by McMillan (1969). The ecotype from the most mesic region of origin also exhibited the largest sensitivity in biomass and BNPP across the gradient due to lower growth in the driest site, as predicted by our hypothesis. This suggests the biomass response of the SIL ecotype may be negligible with a $35 \%$ reduction in growing season precipitation (based on precipitation in 

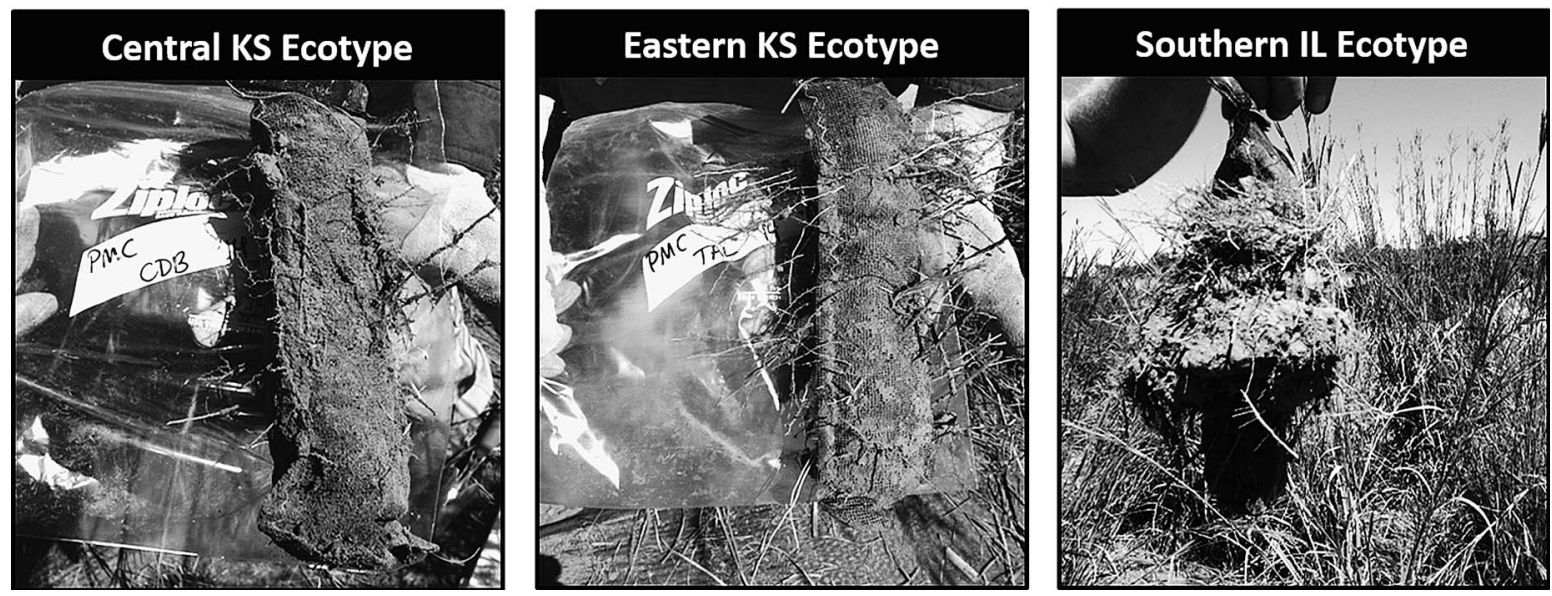

Plate 1. A representative root ingrowth bag from one population of each ecotype harvested at the common garden site in eastern Kansas. Photo credit: M. L. Mendola

eastern Kansas), but will be significantly lower when $50 \%$ of growing season precipitation is received (based on precipitation in central Kansas). Aboveground biomass and BNPP of the EKS ecotype was not affected when $26 \%$ less precipitation was received in central Kansas. This result is consistent with past observations of grass productivity being resistant to variable precipitation inputs in eastern Kansas (Fay et al. 2011). Limited variation in BNPP of both Kansas ecotypes across the gradient in this study also aligns with previous studies that have shown no difference in BNPP between drought and watering treatments in mixed grass prairie (Byrne et al. 2013) and no relationship between C inputs from BNPP and precipitation where eastern Kansas was the most mesic site studied across a longitudinal gradient (McCulley et al. 2005).

Our prediction that the local ecotype would produce more biomass than foreign ecotypes in a given site was only realized in the most mesic ecotype. Despite local adaptation theory predicting superior performance and ultimately fitness of local genotypes at home (Linhart and Grant 1996, Kaweki and Ebert 2004), evidence of no local advantage (Bischoff et al. 2010) and of superior foreign genotypes (Galloway and Fenster 2000, Leiss and Müeller-Schärer 2001) have been documented in reciprocal transplant studies. Including a broader collection of genotypes (to include non-local sources) has been advocated to ensure adequate genetic variation for restored populations to persist in the face of climate change (Broadhurst et al. 2008). However, there has been resistance to this suggestion because a foreign genotype may invade and displace local genotypes (Daehler and Strong 1996) or cause outbreeding depression (Montalvo and Ellstrand 2001). In the central U.S. grassland, climate change is predicted to impose more frequent extreme precipitation events (Christensen and Hewitson 2007), with larger rainfall events and longer periods between events expected
(Polley et al. 2013). Including ecotypes from a more resource-rich region to restore prairie in a historically drier and more drought-prone future would not be considered. This study suggests that using ecotypes from a historically drier region to restore prairie in a more mesic environment could result in lower productivity relative to using mesic-adapted ecotypes in years with average or greater MAP. Productivity might not be compromised in much drier years based on biomass of these ecotypes in central Kansas. The limited responsiveness and lower biomass and BNPP of the driestorigin ecotype across the gradient might limit the competitive ability of this ecotype if planted with mesic-origin ecotypes in mesic conditions (Richter et al. 2012). There is genetic evidence that the local SIL ecotype "wins out" in communities sown with a mixture of the three ecotypes used in this study in southern Illinois (M. Galliart, unpublished data). This occurred with southern Illinois having experienced an "exceptional" drought in 2012 (the most severe drought index classification [United States Drought Monitor 2015]). Maintaining a non-local, dry-origin ecotype in a mesic environment might require limiting competition with the local ecotype. The CKS ecotype initially established well in southern Illinois (Johnson et al., in press) and has persisted in plots sown without the local ecotype of $A$. gerardii (Goad 2012, Wilson 2013). Six years after sowing, the average biomass of $A$. gerardii in communities sown with CKS ecotype was $115 \pm 92 \mathrm{~g} / \mathrm{m}^{2}$, whereas biomass of the local ecotype was $710 \pm 234 \mathrm{~g} /$ $\mathrm{m}^{2}$ in southern Illinois (A. Luebbers and P. Walker, unpublished data). Less dominance of $A$. gerardii could be beneficial for species diversity (McCain et al. 2010). In support of this, Wilson (2013) documented lower plant diversity in prairie sown with the local SIL ecotype compared to prairie sown with the CKS ecotype in southern Illinois. 
Our hypothesis predicted the home vs. away test for local adaptation would only be significant for the most mesic ecotype, which could result from local adaptation to climate or soil. This contrast was significant for all growth responses of the SIL ecotype at home when compared to the farthest away site in central Kansas. Contrary to our hypothesis, there was also evidence of local adaptation when root biomass and BNPP of the EKS ecotype at home was compared to the most resource rich environment in southern Illinois. Root biomass was the only growth response to show a close to significant sympatric vs. allopatric test for local adaptation. Soil may have played a role in this result. There is evidence that AMF are locally adapted to host ecotypes of $A$. gerardii in prairie that has never been cultivated (Johnson et al. 2010) and in formerly cultivated soil restored to prairie ( $\mathrm{Ji}$ et al. 2013).

We have limited understanding of the role of AMF on the results of this study. Two years following this test for local adaptation, root colonization by AMF was measured in one population of each $A$. gerardii ecotype in the southern Illinois common garden. At that time, roots were $36-44 \%$ colonized by AMF and percent colonization was not different among the ecotypes (K. Kazynski, unpublished data). The possibility of disparate effects of agriculture on the soil microbial communities and their recovery in response to $\mathrm{C}_{4}$ grass establishment in different soils and climate conditions among sites (Bach et al. 2010) make plant growth responses from this reciprocal common garden experiment difficult to interpret. This represents a common caveat of testing for local adaptation to climate using multiple sites where soil properties and biota cannot be controlled. We cannot conclude that local adaptation was paramount in the root biomass response because the size of the variance for sympatric vs. allopatric contrast was much smaller than that for ecotype.

Consistent with our hypothesis, the range of trait response (RTR) for aboveground and root biomass in A. gerardii ecotypes increased with MAP in ecotype region of origin when MAP was expected to elicit the higher growth response. There is some theoretical consensus that heterogeneous environments will select for adaptive phenotypic plasticity (Nicotra et al. 2010). We surmise that the high variation in growth and corresponding sensitivity to reduced precipitation in the SIL ecotype across the gradient may be a result of selection in an environment with prolonged saturated conditions and occasional drought. We hypothesize the lack of large differences in growth of the driest-origin ecotype (from central Kansas) in increasingly wetter conditions across the gradient may be a result of directional selection in a more consistently dry environment. The RTR of the driest-origin ecotype, however, may be relatively large, indicating greater sensitivity to less rainfall, when planted in drier conditions (Knapp et al. 2015). The relationship between RTR and MAP of ecotype origin was strengthened for root biomass when the home environment of an ecotype was expected to result in a higher response than a different environment. This is in agreement with results from the sympatric vs. allopatric test for local adaptation. It is possible that variation in locally adapted AMF communities to ecotypes across sites influenced this relationship (Ji et al. 2013).

Plant tissue $\mathrm{C}: \mathrm{N}$ ratio is an important determinant of litter decomposition rate (Cornwell et al. 2008). Thus, ecotypic variation in this root attribute has implications for ecosystem processes. We expected root $\mathrm{C}: \mathrm{N}$ ratio of the SIL ecotype to decrease across the gradient because A. gerardii plants from Illinois have less root branching and lower mycorrhizal dependency relative to plants from Kansas (Schultz et al. 2001), indicative of selection in a more resource-rich environment (Grime 2001). Consistently lower root $\mathrm{C}: \mathrm{N}$ ratio in the SIL and EKS ecotypes across the gradient indicates that these ecotypes are more effective at acquiring $\mathrm{N}$ under a wide range of soil and climate conditions relative to the CKS ecotype. We attribute this to more extensive soil exploration by the greater biomass of roots in the SIL ecotype, and potentially more branching in the EKS ecotype (Schultz et al. 2001). Regardless of environment, the CKS ecotype contained the highest root $\mathrm{C}: \mathrm{N}$ ratio. Selection for high nutrient-use efficiency or specific and locally adapted symbionts in an environment where the $\mathrm{N}$ supply from soil is likely limited by soil moisture may constrain the ability of this ecotype to acquire $\mathrm{N}$ and explain constraints in growth across the gradient. The low root $\mathrm{C}: \mathrm{N}$ ratio and large mass of roots in the SIL ecotype and the high root $\mathrm{C}: \mathrm{N}$ ratio and low mass of roots in the CKS ecotype explained the most and least $\mathrm{N}$ storage in these ecotypes across the gradient, respectively.

\section{Implications and Conclusions}

There is ongoing debate about whether "local" sources are best for reconstructing plant communities that will persist under current and future environmental conditions (Hufford and Mazer 2003, McKay et al. 2005, Broadhurst et al. 2008, Jones 2013). Studying plant responses in their home (or local) and different environments is required to decide whether more ecotypic variation should be included in restorations to mitigate the effects of climate change on ecosystems (Harris et al. 2006). Results from this study can be used to inform the discussion about restoring mesic prairies with ecotypes from drier regions from a functional perspective. The low and limited range or sensitivity in growth of ecotypes from a less resourcerich region, when planted in a more resource-rich region, suggests that ecosystem productivity could be compromised with inclusion of these ecotypes in mesic conditions. Lower productivity in dry years could be exacerbated by less productivity of $\mathrm{C}_{3}$ forbs (less adapted to drought than $\mathrm{C}_{4}$ grasses), which contribute significantly to the structure and functioning of mesic 
prairies in Illinois (Bowles and Jones 2013, Baer et al. 2014). We hypothesize that ecotypes from a much drier region might not persist with local ecotypes from the mesic environment in mixed plantings, but growth is not the only determinant of population persistence. Fitness has been shown to vary significantly among the source populations within each of the ecotypes planted in the southern Illinois common garden (Gibson et al. 2013). Knowledge of fitness and competitive outcomes in intraspecific mixtures could be used to enhance survival of the dry-adapted ecotype in a mesic environment. The role of factors other than climate, such as locally adapted belowground symbionts in the success of non-local ecotypes in restorations, deserves further investigation. A tradeoff to potentially reduced productivity of non-local ecotypes could be higher diversity because dominance of $A$. gerardii suppresses subordinate species that contribute most to diversity in tallgrass prairie. Introducing non-local ecotypes that produce less root biomass and contain higher root tissue $\mathrm{C}: \mathrm{N}$ ratios in that region relative to a local ecotype will also likely alter $\mathrm{N}$ dynamics and the capacity of restorations to rebuild soil organic matter degraded through longterm cultivation, but the direction in which these processes will differ from using local ecotypes will depend on the relative contribution of other species.

This study also suggests our understanding of grassland dynamics in response to precipitation remains incomplete. Knapp et al. (2015) demonstrate that grassland sensitivity to drought decreases exponentially with increasing MAP, using sites ranging from 200 to $900 \mathrm{~mm}$ in MAP. A regionally extended common garden study (to the west) is needed to forecast the response of $A$. gerardii and tallgrass prairie to a greater range of precipitation conditions. The range of growth response in the dominant grass ecotype from the most mesic region in this study when planted into drier regions suggests that grassland sensitivity to drought might be highest in regions characterized by precipitation extremes.

\section{ACKNOWLedgments}

We are grateful for the field and laboratory assistance provided by R. Goad, J. Willand, B. Wodika, R. Klopf, K. Elsenbroek, D. Carpenter, E. McCrea, N. Lelonek, M. Beck, J. Donatelli, and N. Rothwell. The manuscript was greatly improved from the thoughtful comments provided by four reviewers and $\mathrm{S}$. Chapman. This research was funded by the USDA Plants and Abiotic Stress Program (2008-35100-04545), with support from the Konza Prairie Long Term Ecological Research Program.

\section{Literature Cited}

Aitken, S. N., and M. C. Whitlock. 2013. Assisted gene flow to facilitate local adaptation to climate change. Annual Review of Ecology, Evolution, and Systematics 44:367-388.

Aitken, S. N., S. Yeaman, J. A. Holliday, T. Wang, and S. Curtis-McLane S. 2008. Adaptation, migration or extirpa- tion: climate change outcomes for tree populations. Evolutionary Applications 1:95-111.

Avolio, M. L., and M. D. Smith. 2013. Mechanisms of selection: phenotypic differences among genotypes explain patterns of selection in a dominant species. Ecology 94:953965.

Axelrod, D. I. 1985. Rise of the grassland biome, central North America. Botanical Review 51:163-201.

Bach, E. M., S. G. Baer, C. K. Meyer, and J. Six. 2010. Soil texture affects soil microbial and structural recovery during grassland restoration. Soil Biology \& Biochemistry 42:21822191.

Baer, S. G., D. J. Gibson, D. J. Gustafson A. M. Benscoter, L. K. Reed, R. E. Campbell, R. P. Klopf, J. E. Willand, and B. R. Wodika. 2014. No effect of seed source on multiple aspects of ecosystem functioning during ecological restoration: cultivars compared to local ecotypes of dominant grasses. Evolutionary Applications 7:323-335.

Baer, S. G., D. J. Kitchen, J. M. Blair, and C. W. Rice. 2002. Changes in ecosystem structure and function along a chronosequence of restored grasslands. Ecological Applications 12:1688-1701.

Baer, S. G., C. K. Meyer, E. M. Bach, R. P. Klopf, and J. Six. 2010. Contrasting ecosystem recovery on two soil textures: implications for carbon mitigation and grassland conservation. Ecosphere 1:art. 5.

Benson, E. J., and D. C. Hartnett. 2006. The role of seed and vegetative reproduction in plant recruitment and demography in tallgrass prairie. Plant Ecology 187:163-177.

Bischoff, A., T. Steinger, and H. Muller-Scharer. 2010. The importance of plant provenance and genotypic diversity of seed material used for ecological restoration. Restoration Ecology 18:338-348.

Blanquart, F., O. Kaltz, S. L. Nuismer, and S. Gandon. 2013. A practical guide to measuring local adaptation. Ecology Letters 16:1195-1205.

Bowles, M. L., and M. D. Jones. 2013. Repeated burning of eastern tallgrass prairie increases richness and diversity, stabilizing late successional vegetation. Ecological Applications 23:464-478.

Broadhurst, L. M., A. Lowe, D. J. Coates, S. A. Cunningham, M. McDonald, P. A. Vesk, and C. Yates. 2008. Seed supply for broadscale restoration: maximizing evolutionary potential. Evolutionary Applications 1:587-597.

Byrne, K. M., W. K. Lauenroth, and P. B. Adler. 2013. Contrasting effects of precipitation manipulations on production in two sites within the central grassland region, USA. Ecosystems 16:1039-1051.

Christensen, J. H., and B. Hewitson. 2007. Regional climate projections. Pages 847-940 in S. Solomon et al., editors. Climate change 2007: the physical science basis. Contribution of Working Group I to the fourth assessment report of the Intergovernmental Panel on Climate Change. Cambridge University Press, Cambridge, UK.

Collins, S. L., and L. B. Calabrese. 2012. Effects of fire, grazing and topographic variation on vegetation structure in tallgrass prairie. Journal of Vegetation Science 23:563-575.

Cornwell, W. K., et al. 2008. Plant species traits are the predominant control on litter decomposition rates within biomes worldwide. Ecology Letters 11:1065-1071.

Daehler, C. C., and D. R. Strong. 1996. Status, prediction and prevention of introduced cordgrass Spartina spp. invasions in Pacific estuaries, USA. Biological Conservation 78:51-58.

De Frenne, P., et al. 2014. Plant movements and climate warming: intraspecific variation in growth responses to nonlocal soils. New Phytologist. http://dx.doi.org/10.1111/ nph. 12672

Epstein, H. E., W. K. Lauenroth, I. C. Burke, and D. P. Coffin. 1998. Regional productivities of plant species in the Great Plains of the United States. Plant Ecology 134:173-195. 
Fay, P. A., J. M. Blair, M. D. Smith, J. B. Nippert, J. D Carlisle, and A. K. Knapp. 2011. Relative effects of precipitation variability and warming on tallgrass prairie ecosystem function. Biogeosciences 8:3053-3068.

Galloway, L. F., and C. B. Fenster. 2000. Population differentiation in an annual legume: local adaptation. Evolution 54:1173-1181.

Gibson, D. J., G. Sendor, J. Donatelli, S. G. Baer, and L. Johnson. 2013. Fitness among population sources of a dominant species (Andropogon gerardii Vitman) used in prairie restoration. Journal of the Torrey Botanical Society 140:269-279.

Goad, R. K. 2012. Response of regional sources of tallgrass prairie species to variation in climate and soil microbial communities. Thesis. Southern Illinois University, Carbondale, USA.

Gray, M., et al. 2014. Ecotypes of an ecologically dominant grass (Andropogon gerardii) exhibit genetic divergence across the U.S. Midwest grasslands' environmental gradient. Molecular Ecology 23:6011-28.

Grime, J. P. 1998. Benefits of plant diversity to ecosystems: immediate, filter and founder effects. Journal of Ecology 86: 902-910.

Grime, J. P. 2001. Plant strategies, vegetation processes, and ecosystem properties. Second edition. Wiley, New York, New York, USA.

Gustafson, D. J., D. J. Gibson, and D. L. Nickrent. 1999. Random amplified polymorphic DNA variation among remnant big bluestem (Andropogon gerardii Vitman) populations from Arkansas' Grant Prairie. Molecular Ecology 8: 1693-1701.

Harris, J. A., R. J. Hobbs, E. Higgs, and J. Aronson. 2006. Ecological restoration and global climate change. Restoration Ecology 14:170-176.

Hayes, D. C., and T. R. Seastedt. 1987. Root dynamics of tallgrass prairie in wet and dry years. Canadian Journal of Botany 65:787-791.

Hufford, K. M., and S. J. Mazer. 2003. Plant ecotypes: genetic differentiation in the age of ecological restoration. Trends in Ecology Evolution 18:147-155.

Ji, B., C. A. Gehring, G. W. T. Wilson, R. M. Miller, L. FloresRenteria, and N. C. Johnson. 2013. Patterns of diversity and adaptation in Glomeromycota from three prairie grasslands. Molecular Ecology 22:2573-2587.

Johnson, L. C., et al. In press. Intraspecific variation of a dominant grass and local adaptation in reciprocal common garden communities along a US Great Plains precipitation gradient: implications for grassland restoration with climate change. Evolutionary Applications.

Johnson, L. C., and J. R. Matchett. 2001. Fire and grazing regulate belowground processes in tallgrass prairie. Ecology 82:3377-3389.

Johnson, N. C., G. W. T. Wilson, M. A. Bowker, J. A. Wilson, and R. M. Miller. 2010. Resource limitation is a driver of local adaptation in mycorrhizal symbioses. Proceedings of the National Academy of Sciences USA 107:2093-2098.

Jones, T. A. 2013. Ecologically appropriate plant materials for restoration applications. BioScience 63:211-219.

Kawecki, T. J., and D. Ebert. 2004. Conceptual issues in local adaptation. Ecology Letters 7:1225-1241.

Keeler, K. H., B. Kwankin, P. W. Barnes, and D. W. Galbraith. 1986. Detection of polyploid polymorphism in big bluestem (Andropogon gerardii). American Journal of Botany 73:686686.

Knapp, A. K., J. M. Briggs, and J. K. Koelliker. 2001. Frequency and extent of water limitation to primary production in a mesic temperate grassland. Ecosystems 4: $19-28$.

Knapp, A. K., C. J. W. Carroll, E. M. Denton, K. J. La Pierre, S. L. Collins, and M. D. Smith. 2015. Differential sensitivity to regional-scale drought in six central U.S. grasslands. Oecologia 177:949-957.

Lauenroth, W. K., I. C. Burke, and M. P. Gutmann. 1999. The structure and function of ecosystems in the central North American grassland region. Great Plains Research 9:223259 .

Leiss, K. A., and H. Müeller-Schärer. 2001. Performance of reciprocally sown populations of Senecio vulgaris from ruderal and agricultural habitats. Oecologia 128:210-216.

Liancourt, P., L. A. Spence, D. S. Song, A. Lkhagva, A. Sharkhuu, B. Boldgiv, B. R. Helliker, P. S. Petraitis, and B. B. Casper. 2013. Plant response to climate change varies with topography, interactions with neighbors, and ecotype. Ecology 94:444-453.

Linhart, Y. B., and M. C. Grant. 1996. Evolutionary significance of local genetic differentiation in plants. Annual Review of Ecology and Systematics 27:237-277.

Littell, R. C., G. G. Milliken, W. W. Stroup, and R. D. Wolfinger. 2006. SAS system for mixed models. SAS Institute, Cary, North Carolina, USA.

Lowry, D. B. 2012. Ecotypes and the controversy over stages in the formation of new species. Biological Journal of the Linnean Society 106:241-257.

Lunt, I. D., M. Byrne, J. J. Hellmann, N. J. Mitchell, S. T. Garnett, M. W. Hayward, T. G. Martin, E. McDonaldMaddden, S. E. Williams, and K. K. Zander. 2013. Using assisted colonisation to conserve biodiversity and restore ecosystem function under climate change. Biological Conservation 157:172-177.

McCain, K. N. S., S. G. Baer, J. M. Blair, and G. W. T. Wilson. 2010. Dominant grasses suppress local diversity in restored tallgrass prairie. Restoration Ecology 18:40-49.

McCulley, R. L., I. C. Burke, J. A. Nelson, W. K. Lauenroth, A. K. Knapp, and E. F. Kelly. 2005. Regional patterns in carbon cycling across the Great Plains of North America. Ecosystems 8:106-121.

McKay, J. K., C. E. Christian, S. Harrison, and K. J. Rice. 2005. "How local is local?" A review of practical and conceptual issues in the genetics of restoration. Restoration Ecology 13:432-440.

McLean, E. H., S. M. Prober, W. D. Stock, D. A. Steane, B. M. Potts, R. E. Vaillancourt, and M. Byrne. 2014. Plasticity of functional traits varies clinally along a rainfall gradient in Eucalyptus tricarpa. Plant Cell and Environment 37:14401451.

McMillan, C. 1959. The role of ecotypic variation in the distribution of the central grassland of North America. Ecological Monographs 29:285-308.

McMillan, C. 1964. Ecotypic differentiation within four North American prairie grasses. I. Morphological variation within transplanted community fractions. American Journal of Botany 51:1119-1128.

McMillan, C. 1965. Ecotypic differentiation within four North American prairie grasses. II. Behavioral variation within transplanted community fractions. American Journal of Botany 52:55-65.

McMillan, C. 1967. Phenological variation within seven transplanted grassland community fractions from Texas and New Mexico. Ecology 48:807-813.

McMillan, C. 1969. Ecotypes and ecosystem function. BioScience 19:131-134.

Montalvo, A. M., and N. C. Ellstrand. 2001. Nonlocal transplantation and outbreeding depression in the subshrub Lotus scoparius (Fabaceae). American Journal of Botany 88: 258-269.

Nicotra, A. B., et al. 2010. Plant phenotypic plasticity in a changing climate. Trends in Plant Science 15:684-692.

Nippert, J. B., R. A. Wieme, T. W. Ocheltree, and J. M. Craine. 2012. Root characteristics of C-4 grasses limit reliance on 
deep soil water in tallgrass prairie. Plant and Soil 355:385394.

Norrmann, G. A., C. L. Quarin, and K. H. Keeler. 1997. Evolutionary implications of meiotic chromosome behavior, reproductive biology, and hybridization in $6 \mathrm{X}$ and $9 \mathrm{X}$ cytotypes of Andropogon gerardii (Poaceae). American Journal of Botany 84:201-207.

Olsen, J. T., K. L. Caudle, L. C. Johnson, S. G. Baer, and B. R. Maricle. 2013. Environmental and genetic variation in leaf anatomy among populations of Andropogon gerardii (Poaceae) along a precipitation gradient. American Journal of Botany 100:1957-1968.

Polley, H. W., D. D. Briske, J. A. Morgan, K. Wolter, D. W. Bailey, and J. R. Brown. 2013. Climate change and North American rangelands: trends, projections, and implications. Rangeland Ecology \& Management 66:493-511.

Richardson, A. D., P. M. S. Ashton, G. P. Berlyn, M. E. McGroddy, and I. R. Cameron. 2001. Within-crown foliar plasticity of western hemlock, Tsuga heterophylla, in relation to stand age. Annals of Botany 88:1007-1015.

Richter, S., T. Kipfer, T. Wohlgemuth, C. Calderón Guerrero, J. Ghazoul, and B. Moser. 2012. Phenotypic plasticity facilitates resistance to climate change in a highly variable environment. Oecologia 169:269-279.

Risser, P. G., E. C. Birney, H. D. Blocker, S. W. May, W. J. Parton, and J. A. Wiens. 1981. The true prairie ecosystem. Hutchinson and Ross, Stroudsburg, Pennsylvania, USA.

Sala, O. E., W. J. Parton, L. A. Joyce, and W. K. Lauenroth. 1988. Primary production of the central grassland region of the United States. Ecology 69:40-45.

Samson, F., and F. Knopf. 1994. Prairie conservation in North America. BioScience 44:418-421.

SAS Institute. 2011. SAS version 9.3. SAS Institute, Cary, North Carolina, USA.
Savolainen, O., M. Lascoux, and J. Merila. 2013. Ecological genomics of local adaptation. Nature Reviews Genetics 14: $807-820$.

Schultz, P. A., R. M. Miller, J. D. Jastrow, C. V. Rivetta, and J. D. Bever. 2001. Evidence of a mycorrhizal mechanism for the adaptation of Andropogon gerardii (Poaceae) to high- and low-nutrient prairies. American Journal of Botany 88:1650 1656.

Smith, F. A., E. J. Grace, and S. E. Smith. 2009. More than a carbon economy: nutrient trade and ecological sustainability in facultative arbuscular mycorrhizal symbioses. New Phytologist 182:347-358.

Smith, M. D., and A. K. Knapp. 2003. Dominant species maintain ecosystem function with non-random species loss. Ecology Letters 6:509-517.

United States Drought Monitor. 2015. U.S. drought monitor classification scheme. National Drought Mitigation Center, Lincoln, Nebraska, USA. http://droughtmonitor.unl.edu/ AboutUs/ClassificationScheme.aspx

Weeks, A. R., C. M. Sgro, A. G. Young, R. Frankham, N. J. Mitchell, K. A. Miller, et al. 2011. Assessing the benefits and risks of translocations in changing environments: a genetic perspective. Evolutionary Applications 4:709-725.

Wilson, L. M. 2013. Plant community response to regional sources of dominant grasses in grasslands restored across a longitudinal gradient. Thesis. Southern Illinois University, Carbondale, Illinois, USA.

Zhang, K., L. Johnson, R. Nelson, W. Yuan, Z. Pei, and D. Wang. 2012. Chemical and elemental composition of big bluestem as affected by ecotype and planting location along the precipitation gradient of the Great Plains. Industrial Crops and Products 40:210-218.

\section{Supplemental Material}

Ecological Archives

The Appendix is available online: http://dx.doi.org/10.1890/14-1492.1.sm 